* Corresponding autho

Phone +421556022469

E-mail address:zdenkobobovsky@tukesk

(Ing. Zdenko Bobovský, PhD.)

Article information

Article history: AMS-Volume16-No.3-00148-12

Received 16 June 2012

Accepted 11 August 2012

\section{Self-Reconfigurable Modular Robotic System}

\author{
Zdenko Bobovský ${ }^{1 *}$, František Trebuňa ${ }^{1}$, Juraj Smrček ${ }^{2}$ \\ ${ }^{1}$ Technical University of Kosice, Faculty of Mechanical Engineering, Department of Applied Mechanics and Mechatronics, Letna 9, 04200 \\ Kosice, Slovakia \\ ${ }^{2}$ Technical University of Kosice, Faculty of Mechanical Engineering, Department of Production Systems and Robotics, Němcovej 32, 04200 \\ Kosice, Slovakia
}

\section{BIOGRAPHICAL NOTES}

Ing. Zdenko Bobovský, PhD. is an assistant of the Department of Applied Mechanics and Mechatronics at Faculty of Mechanical Engineering at Technical University of Košice. He received B.Sc. degree in production systems with industrial robots and manipulators (2002), M.Sc degree in Construction of robotics system (2005), M.Sc degree in automotive production (2007), Medal of Dean for excellent student (2007) and Ph.D in Production system at the same faculty (2009). His current fields of interest are mechatronics, metamorphous self-reconfigurable modular robotic systems and applied mechanics.

Dr.h.c. mult. prof. Ing. František Trebuňa, CSc. is a professor of applied mechanics, Head of the Department of Applied Mechanics and Mechatronics and Dean of the Faculty of Mechanical Engineering. He is author of 10 monographs, 12 university textbook, special book publications, 12 university notebooks and more than 300 publications in journals and conference proceedings at Slovakia abroad. He is author of important projects and engineering works. He received several prizes at home and abroad. He received three titles Doctor Honoris Causa (DHC) including two from foreign universities for the development of applied mechanics and mechatronics.

prof. Ing. Juraj Smrček, PhD. is a full professor and a head of Division of robotics at Department of Production systems and robotics at Technical University of Košice, Slovakia. He received the M.Sc. and Ph.D. degrees from the Faculty of Mechanical Engineering at the same university in 1964, and 1983, respectively. He is a co-founder of Department of robotics (1988). From year 1993 he worked as lecturer, solutionist, chairman of state assignments, and experimental researcher and developer of robots. He received the prof. degree in production systems with industrial robots and manipulator in 2000. His current fields of interest are service robotics and metamorphous self-reconfigurable modular robotic systems.

\section{KEY WORDS}

Kinematics, self-reconfigurable, metamorphic, modular, robotic system.

\section{ABSTRACT}

Theory of mechanisms with variable structure in robotic applications of self-reconfigurable structures is one of directions of robot development. At our faculty is in development self-reconfigurable modular robotic system capable of rebuilding a structure according to requirements of the current task. We have designed an algorithm based on transformation matrixes (TM), an accuracy and a functionality was verified in mathematical programs MathCad ${ }^{\oplus}$ and than in a first application created in Mat- 
$\mid a b^{\oplus}$. Plotting the position of the local coordinate systems (LCS) in the area at the move of the one of the modules and comparing with the tracks from SolidWorks-CosmosMotion ${ }^{\oplus}$ it was found that the curve along which LCS moves are identical and the TM is properly designed to determine the exact position of each LCS. The TM was implicated in the application written in C\# and designed to simulate the behaviour of the self-reconfigurable modular system. The application allows changing the connections between modules, which are then automatically converted to the new TM for new kinematics structure. Mathematical notations of TM for each sub-module allows to the connection of sub-modules according to requirements of the current task of the system and still have position and orientation vectors to any LCS at a momentary kinematics structure.

\section{Introduction}

A basic building block of each metamorphic modular robotic system (MMRS) is module. A possibilities of the module, number of modules and type of the module determined the resulting properties of the system. Using identical modules leads to a homogeneous MMRS, whose main advantage is low cost. Using different types leads to a heterogeneous MMRS, whose main advantages are low dimensions and the possibility of extending properties of the system by adding a new module with the new properties. In homogeneous system, each module must contain logic elements, sensors, power supply and motors. In heterogeneous systems are individual modules with logic elements, modules with power supply, mechanical modules that perform the movement action and modules that determine additional properties of the system. Advantages of modular robotics are obvious only with respect to which the required tasks should be applied to several special-purpose robots, or where the environment and tasks ahead cannot be fully defined [3]. Therefore it is appropriate to propose the module, respectively modules that could meet the maximum amount of the required tasks. The complex module is easier to modify its control - individual algorithm. So to achieve the maximum amount of useful applications such as design module and MMRS capabilities with minimal changes, and then determine that the proposed module design have restricted possible application.
Currently, there are several modular robotic systems capable of automatic transformation, this is done by predefined tables and predefined shapes of possible structures. Present results in solving MMRS show that is possible to design a module that has a high degree of adjustability, works in 3D space and can support a chain and lattice structure while supports heterogeneity of MMRS.
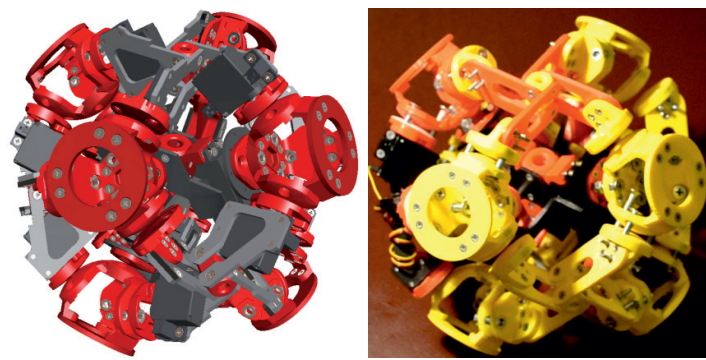

Fig. 1: CAD model and physical model of module MG.

\section{Description of module kinematics}

Description of MMRS kinematics is based on the description of kinematics of each module. Description of module describes the dependences between the local coordinate systems (LCS) defined on module. It can by defined by Denavit -Hartengerg matrix [1] or with matrix method through transformation matrix (TM) $[2,3]$. Then depending on the location and orientation of the connection is calculated the kinematic of the new structure or just the changed section of system.
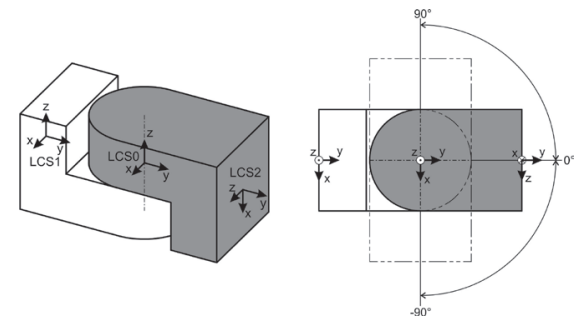

Fig. 2: Module with one degree of freedom

The number of connection places, number of degree of freedom (DOF) and type of connection mechanism, determined the complexity of the kinematic description. The module with one DOF and two connection surfaces, Fig.2, which has only one possible orientation. Has description of kinematics with TM from LCS1 to LCS2 in Eq.1, and from LCS2 to LCS1 in Eq.2.

$A=\operatorname{Tp}_{y}(L / 2) * \operatorname{Tr}_{z}(q i) * T p_{y}(L / 2) * \operatorname{Tr}_{y}(\pi / 2) \quad(1)$ 
$A_{\text {inv }}=\operatorname{Tr}_{y}(-\pi / 2) * T p_{y}(-L / 2) * \operatorname{Trz}\left(-q_{i}\right) * T p_{y}(-L / 2)$

where: $\operatorname{Tr}_{y}(X)$ - TM for the $Y$-axis rotation of the argument $X, T p_{y}(X)$ - TM for the $Y$-axis displacement of the a argument $X, \operatorname{Tr}_{z}(X)$ - Tm for the Z-axis rotation of the argument $X, q_{i}$ - unknown variable (degree of rotation), $i$ - ID number of module, $L$ - distance between LCS1 and LCS2 resp. module length, Index inv marking matrix A means that is an inverse calculation (inv - inversion).

With number of connection places on the module, the possible connections to the modules and the number of degrees of freedom per module, increase the complexity of description of the kinematics structure MRS. In case of simple modules is possible to describe the dependences between connection places. In complex modules can by used a description between connection mechanisms or the description from LCS, to LSC. Then from connection places we obtain dependences for the connection place $i$ to connection place $j$, by multiplying the LCS to LCS and the inverse multiplication LCS to LCS.

\section{Calculation of the kinematic structure}

Calculation of the kinematic structure is made from basic module, where the location of that module id either given by the functions that MMRS performs or depends on the type of MMRS. In heterogeneous MMRS calculation can be defined only by certain types of modules, like control module. In the module show above can be defined as the main module can by defined any module of MMRS, where the description of the structure is based just for matrix multiplication $A\left(q_{i}\right)$ and $\operatorname{Ain}\left(q_{i}\right)$, because this type can only create a serial structure.
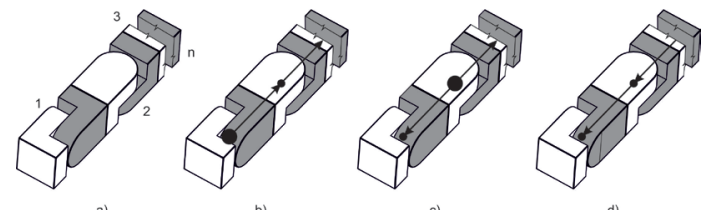

Fig. 3: Serial connection of modules and kinematic structure description.

The actual description depends on the defined position of the main module, Fig.3a) shows how the main module, module that is placed at one end of a serial structure, oriented with LCS2 toward the structure. For LCS2 is valid Eq.3, the position of
LCS2 on second module is valid, Eq. 4. For LCS2 of n-module is valid Eq. 6 etc. In defining the main module in the inner part of the serial structure of Fig. 3c) a description of each module is defined by Eq. 5 for LCS1 direction of the main module and Eq. 6 for LCS2 direction of the main module. In defining the main module at the end of the serial structure for LCS1 oriented to structure is Eq. 7, valid for all connected module.

$$
\begin{aligned}
& A_{1,2}=A\left(q_{1}\right) * A\left(q_{2}\right) \\
& A_{1,3}=A\left(q_{1}\right) * A\left(q_{2}\right) * A\left(q_{3}\right)=A_{1,2} * A\left(q_{3}\right) \\
& A_{n, n-i}=A_{i n v}\left(q_{n}\right) * A_{i n v}\left(q_{n-1}\right) * \ldots * A_{i n v}\left(q_{n-i}\right) \\
& A_{n, n+j}=A\left(q_{n}\right) * A\left(q_{n+1}\right) * \ldots * A\left(q_{n+j}\right) \\
& A_{n, 1}=A_{i n v}\left(q_{n}\right) * A_{i n v}\left(q_{n-1}\right) * \ldots * A_{i n v}\left(q_{1}\right)
\end{aligned}
$$

These relationships are valid only for modules involved in the order of 1 to $\mathrm{n}$. For any module connection, the variables qi are defined by the module ID.

The functionality and accuracy of TM was verified in mathematical programs MathCad ${ }^{\circledR}$ and Matlab, where the calculation for two and more connected modules was made, and then was made calculation for complex kinematics structures, Fig. 4.

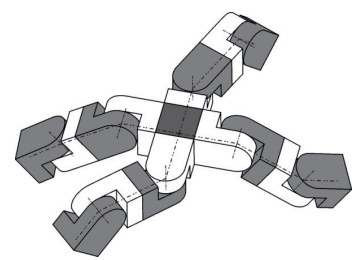

a

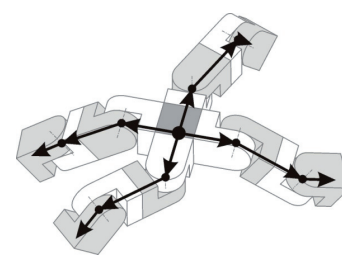

c

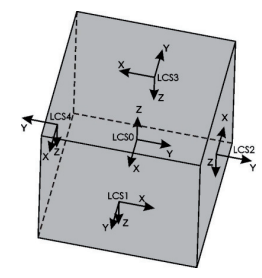

b

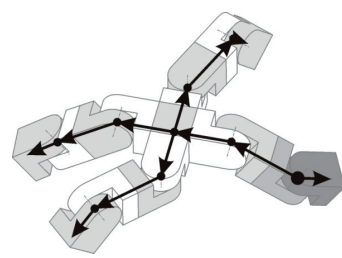

d
Fig. 4: Testing assembly of modules with 8 DOF, a - robot with 8 modules and one additional with O DOF, $b$ - additional module with 4 connection places, c-additional module is defined like main module, $d$ - end module of one leg is defined like main module orientation of arrow shows the process of calculation. 
From these calculations were subsequently obtained TM, a position and orientation vectors. An additional plotting of the position of these LCS in space of modules and comparing LCS with trace from SolidWorks - CosmoMotion found that the curve along which they move LCS are identical, and that TM is properly designed to determine exact position of each LCS.

\section{Module MG}

Presented procedure for defining kinematic structure is in principle applicable to various types of modular robotic systems, whether homogeneous or heterogeneous, where depending on the complexity of modules, increasing the complexity of defining modules and then describes the actual structure for the MMRS. Trends in development of these systems suggest need to address the issue of automatic description of kinematic structure. It is economically preferable to have an open modular system capable of automatically changing the structure as necessary as having a closed system with clearly defined possible kinematics structures and one algorithm to change between them. Modularity allows for open systems also add new types of modules to already existing systems.

TM description introduced in the previous section is used at Department of Applied mechanics and mechatronics to development of the MMRS $[7,8,9]$. These TM have been implicated in application designed to simulate the behavior of the MMRS. The module allows interacting with other modules, changing its own kinematic structure and also divided into small parts that would be able to cooperate with others modules. The shape is designed to easy change kinematic structure to various forms of unlimited functionality. The Fig. 5 shows two kinematic structures made only from sub-modules.

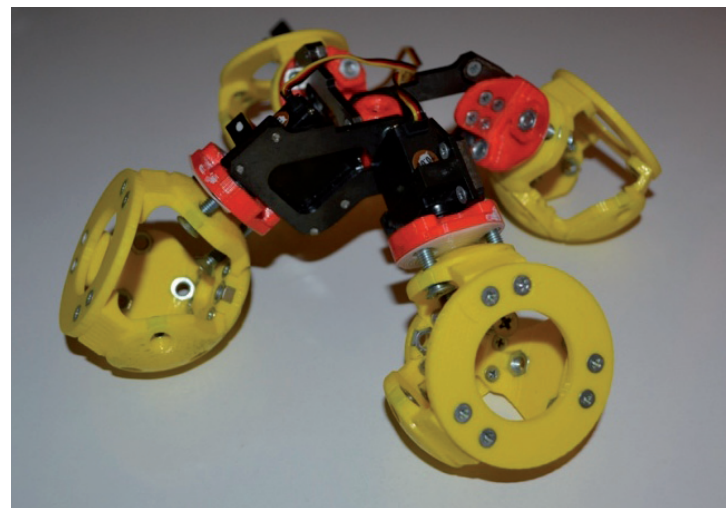

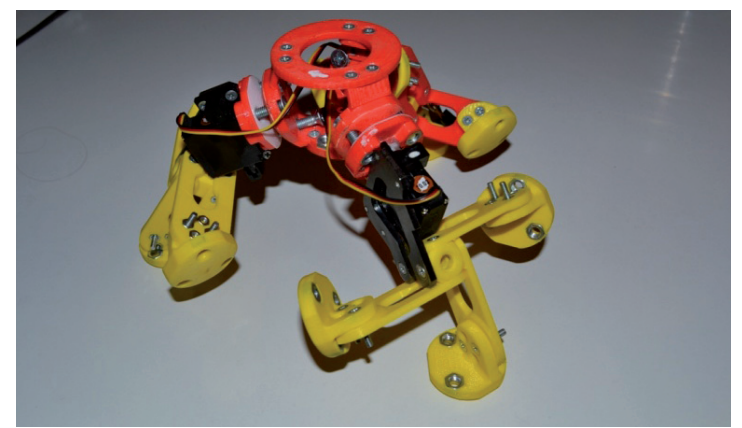

Fig. 5: Examples of kinematics structures compound from a few sub-modules.

The described approach of calculation allows in application change the connection between modules, which are then automatically, calculated new TM for a newly created kinematic structure. It is possible to change Main module, from which is there a calculation of TM. The application supports the creation of serial and parallel mechanisms. Fig 6 shows movement of MG module.

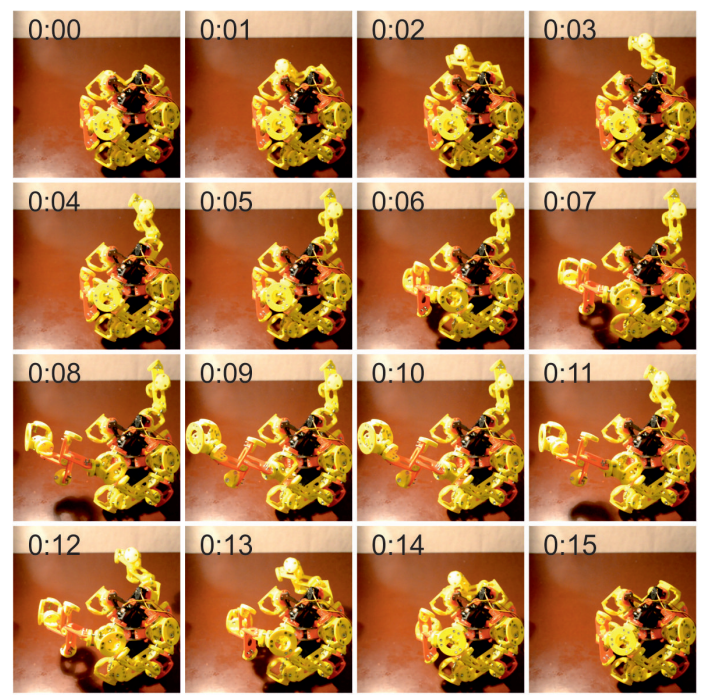

Fig. 6: Shape changing of module MG.

\section{Conclusion}

Mathematical notation of transformation matrixes for each sub-modules allows the connection of submodules according to requirements of the role that currently the system does and still have a position and orientation vectors of LCS of any module in momentary kinematic structure. Self-reconfigurable modular robotic systems have great potential appli- 
cations, but only if this system will replace a large number of specific robots. Our proposed system has features that allow replacing the large number of specific robots. The module supports a high degree of adjustability and also the sub-modules allows to create other modules that can work even with a reduced number of sub-modules. To have the full possibility of the module and its sub-modules is neces sary to know the position and orientation vectors of LCS. For this we have TM presented in this contribution. For a full possibility control of such a system is necessary to solve the inverse kinematics and many other algorithms that make then able to automatic regulation, control and maintenance of MMRS.

\section{Acknowledge}

The paper has been created realization of project APVV-0091-11 and of project applied study STIMULY "Comprehensive modular medium category robotic system with enhanced intelligence".

\section{References}

[1] Skařupa, J., Mostýn, L.: Teorie průmyslových robotů, Strojnícka fakulta TU v Košiciach, Vienala Košice, 2003, ISBN 8088922-35-6,

[2] Brát, V:: Maticové metódy v analýze a syntéze prostorových vázaných mechanických systému. Praha 1981,

[3] Brát, V. - Rosenbert, J. - Jáč, V.: Kinematika, STNL Praha, 1987,

[4] D. Marbach, A.J. Ijspeert, F. Groen et al., Coevolution of configuration and control for homogenous modular robot, In: Proceedings of the Eighth Conference on Intelligent Autonomous Systems (IAS8), 2004, pp. 712-719, IOS Press,

[5] K. Stoy, Emergent Control of Self-Reconfigurable Robots, Ph.D. Thesis, AdapTronics Group, The Maersk Mc-Kinney Moller Institute for Production Technology, University of Southern Denmark,

[6] Yim, M.; Wei-Min Shen; Salemi, B.; Rus, D.; Moll, M.; Lipson, H.; Klavins, E.; Chirikjian, G.S.; Modular Self-Reconfigurable Robot Systems: Grand Challenges of Robotics, Robotics \& Automation Magazine, IEEE, Volume 14, Issue 1, March 2007, pp. 43-52,

[7] Bobovský Z:: Návrh robota s metamorfnou kinematickou štruktúrou : dizertačná práca ; školitel' Juraj Smrček. - Košice, 2009. - 172 s.,

[8] Trebuňa, F., Smrček, J., Bobovský Z:: The Influence of Shape for Self-Reconfigured Modular Robotic System Characteristics, In: Acta Mechanica Slovaca. Roč. 14, č. 1 (2010), s. 6-12. - ISSN 1335-2393,

[9] Trebuňa, F., Smrček, J., Bobovský Z:: Kinematics of self-reconfigurable robotic system, In: Acta Mechanica Slovaca. Roč.

14, Č. 4 (2010), s. 36-41. - ISSN 1335-2393.

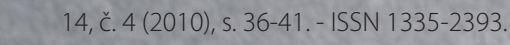

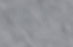

\footnotetext{
(1)
}

(1)

.

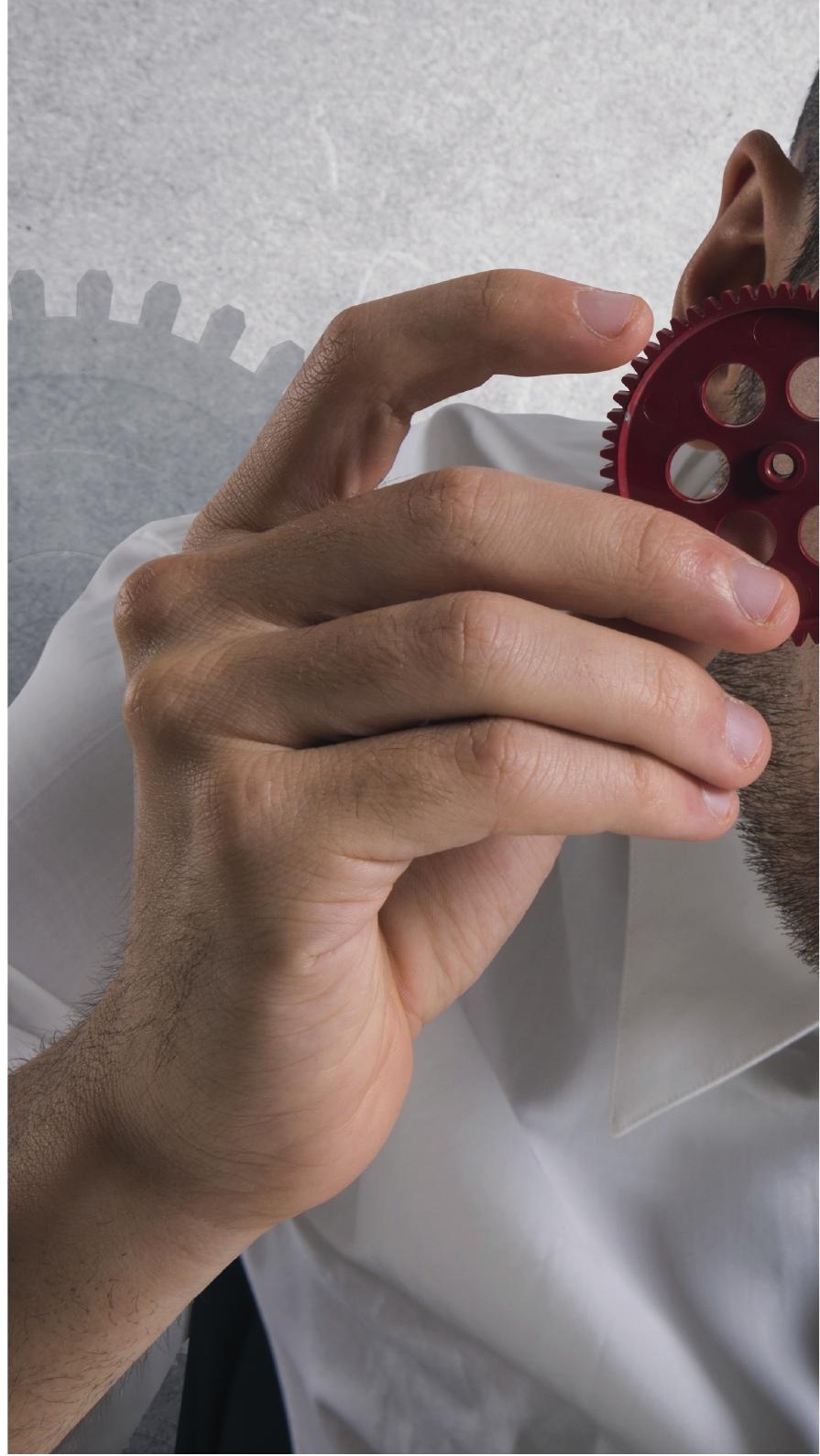


